\title{
LUT
}

University

\section{lon exchange recovery of rhenium from industrially relevant sulfate solutions: Single column separations and modeling}

\author{
Virolainen Sami, Laatikainen Markku, Sainio Tuomo
}

This is a Final draft version of a publication

published by Elsevier

in Hydrometallurgy

DOI: $10.1016 /$ j.hydromet.2015.09.026

Copyright of the original publication: ( 2015 Elsevier B.V.

Please cite the publication as follows:

Virolainen, S., Laatikainen, M., Sainio, T., 2015. Ion exchange recovery of rhenium from industrially relevant sulfate solutions: single column separations and modeling. Hydrometallurgy 158, 74-82. doi:10.1016/j.hydromet.2015.09.026

This is a parallel published version of an original publication. This version can differ from the original published article. 
Ion exchange recovery of rhenium from industrially relevant sulfate solutions: single column separations and modeling

\author{
Sami Virolainen ${ }^{\mathrm{a}, *}$, Markku Laatikainen ${ }^{\mathrm{a}}$, Tuomo Sainio ${ }^{\mathrm{a}}$ \\ ${ }^{a}$ Lappeenranta University of Technology, Laboratory of Separation Technology, P.O. Box 20, FI-53851 \\ Lappeenranta, Finland \\ *Corresponding author.Tel.: +358 40 7093444, E-mail address: Sami.Virolainen@lut.fi
}




\begin{abstract}
In this study, phenomena behind recovery of Re by weak anion exchangers from sulfate solutions containing Mo and As as impurities were investigated. All the metals exist as different kinds of oxyanions or, at some conditions, cations, meaning that several phenomena need to be taken into account. Batch uptake kinetics and dynamic breakthrough experiments were conducted with three commercial resins, and a model based on competitive Langmuir isotherm and an approximate diffusion equation was used to describe competitive sorption of the oxyacids. The separation systems are also discussed in relation to thermodynamic properties of the related oxyanions.
\end{abstract}

The ability of the anion exchangers to adsorb Re from concentrated sulfate solutions is related to the size and degree of hydration of perrhenate anion, $\mathrm{ReO}_{4}^{-}$. Especially high $\mathrm{Re}$ equilibrium capacities of the Purolite A170 and gel-type A172 resins are related to their complex amine functional group, which favors less charged and more hydrophobic anions. However, the functionality did not explain the superior Re/Mo selectivity of the A172 resin detected especially in dynamic column experiments. Diffusion coefficients of all components were remarkably low in A172, and the measured moisture content of the resin was also low. These observations lead to a conclusion that the physical structure of the A172 is so dense that Mo species can only enter near the surface of the resin particle, which is the cause to a low uptake. Both of the Purolite resins also had a good Re/As selectivity, and are well suited for recovering Re from acidic sulfate solutions not containing Mo that are common in industrial applications. 
Keywords

Rhenium; Molybdenum; Sulfate solution; Anion exchange; Modeling; Speciation chemistry

\section{Abbreviations}

ICP-AES inductively coupled plasma atomic emission spectroscopy

\section{Notation}

$\begin{array}{ll}\varepsilon_{\mathrm{b}} & \text { bed porosity, - } \\ \rho_{\mathrm{s}} & \text { density of resin, } \mathrm{g} / \mathrm{L} \\ D_{\mathrm{ax}} & \text { axial dispersion coefficient, } \mathrm{m}^{2} / \mathrm{s} \\ D_{\mathrm{p}} & \text { pore diffusion coefficient in macroporous resins, } \mathrm{m}^{2} / \mathrm{s} \\ D_{\mathrm{s}} & \text { apparent diffusion coefficient in swollen resin gel, } \mathrm{m}^{2} / \mathrm{s} \\ K & \text { affinity constant in NICA model, L/mol } \\ Q_{\mathrm{max}} & \text { maximum adsorption capacity, eq/L } \\ R_{\mathrm{p}}, & \text { radius of resin particle, } \mu \mathrm{m} \\ V_{\mathrm{b}} & \text { volume of resin bed, } \mathrm{mL} \\ V_{\mathrm{L}} & \text { liquid volume, L } \\ V_{\mathrm{S}} & \text { resin volume, } \mathrm{L} \\ c_{p} & \text { concentration in macroporous resin, mol/L } \\ \bar{c}_{p} & \text { average pore solution concentration in macroporous resin, mol/L } \\ c & \text { concentration in liquid phase, mol/L } \\ d_{\mathrm{p}} & \text { pore diameter in macroporous resin, } \mathrm{m} \\ d_{\mathrm{s}} & \text { diameter of resin particle for gel-type resin, } \mathrm{m} \\ m_{\mathrm{ads}} & \text { adsorbed amount, mg } \\ q & \text { concentration in gel-type resin, mol/L } \\ q & \text { concentration in resin bed, mg/mL bed } \\ \bar{q} & \text { volume-averaged concentration in gel-type resin, mol/L } \\ t & \text { time, s or min } \\ v & \text { interstitial flow velocity, m/s } \\ x & \text { axial coordinate, m }\end{array}$

\section{Sub- and superscripts}

$\begin{array}{ll}* & \text { equilibrium } \\ 0 & \text { concentration in resin pretreatment } \\ \text { elu } & \text { elution results } \\ \text { feed } & \text { index for feed concentration } \\ \mathrm{i}, \mathrm{j}, \mathrm{k} & \text { indexes for metals' concentrations and sampling points } \\ \text { load } & \text { intake values calculated from measured breakthrough curves } \\ \text { sim } & \text { simulated intake values }\end{array}$




\section{Introduction}

Rhenium, Re, is mainly used in superalloys of turbine engines and catalysts of petrochemical industry. $\mathrm{Re}$ is found in molybdenum and copper ores, from which production was 53 tons in 2013 (United States Geological Survey, 2014). Over 50\% of Re is recycled from its end products (Graedel et al., 2011). Price of Re has been fluctuating between 2000 and 12000 \$/kg in 21 $1^{\text {st }}$ century ("Material Processing Technology - News Listing," 2014) and is currently 2900 \$/kg (“Metal pages,” 2014).

Anderson et al. (2013) provide in their recent review article extensive information about industrially relevant Re recovery processes. In pyrometallurgical treatment of ores $\mathrm{Re}$ is enriched to flue gases, from which it is leached by washing with water or $\mathrm{H}_{2} \mathrm{SO}_{4}$. Recovery of Re from such solutions with precipitating as $\mathrm{KReO}_{4}$ was suggested already in 1947 by Melaven and Bacon (1947). Later ion exchange (Chmielarz et al., 2010; Sutulov, 1965) or solvent extraction has been used for the recovery (Abisheva et al., 2011; Churchward and Rosenbaum, 1963; Zagorodnyaya et al., 2008). Re is also found in leachates of Mo, Cu and $\mathrm{U}$, from which is it may be recovered by ion exchange, solvent extraction or activated carbon adsorption (Coltrinari et al., 2000; Goddard, 1983; Waterman et al., 2010; Zagorodnyaya et al., 2013). Recently recovery of Re from high-viscosity oil and bitumen has been suggested (Troshkina et al., 2011). Ion exchange is also an important unit operation when recovering Re from wastes, such as petrochemical catalysts (Kasikov and Petrova, 2009) and scrap alloys (Elutin et al., 1997; Heshmatpour and McDonald, 1982; Olbrich et al., 2008; Stoller et al., 2008; Srivastava et al., 2014). In general, ion exchange has been recently shown to be a potential recovery, separation and purification method for 
small amounts of valuable metals in hydrometallurgical side streams (Sole et al., 2011; Zhao et al., 2012; Virolainen et al., 2013; Virolainen et al., 2014; Virolainen et al., 2015).

Anion exchangers are used as ion exchange materials for Re, because it exists in aqueous solutions almost always as perrhenate anion, $\mathrm{ReO}_{4}^{-}$. A variety of different resins have been studied since 1950's especially in former Soviet Union, though the main focus has been on weak anion exchangers. Especially a hexamethylenediamine functionalized resin AN-21 gained attention (Lebedev and Tyurekhodzaeva, 1966; Zagorodnyaya et al., 2008, 1970), and also industrial scale applications have been reported (Mekler, 1975). Weak anion exchangers are preferred because of the possibility of elution with $\mathrm{NH}_{3}$, resulting a marketable product $\mathrm{NH}_{4} \mathrm{ReO}_{4}$ (Kholmogorov et al., 1999). Of particular importance in materials selection is selectivity for Re over elements that form similar oxyanions; including As, Mo, Pt, Se, Tc, V, W. Especially Re/Mo selectivity is critical since these metals occur together in the nature.

Variety of potential industrial $\mathrm{SO}_{4}{ }^{2-}$ solutions for Re recovery has been reported by Mikhaylenko and Blokhin (2012). Currently secondary amine functional Purolite A172 and A170 are industrially used for these. A170 is used for example in KGHM Ecoren S.A. (Poland) for Re recovery from washing acids of $\mathrm{Cu}$ smelter flue gases (Chmielarz et al., 2010), and ASARCO has patented and piloted an ion exchange process utilizing A170 for Re recovery from $\mathrm{Cu}$ leachates (Nebeker and Hiskey, 2012; Nebeker, 2012). A172 is known to have significantly better Re/Mo selectivity than A170 (Blokhin et al., 2011; Mikhaylenko, 2011), and is thus preferred for such solutions. These authors explain the selectivity with steric effects; Mo-oxyanions are so large that they do not fit to the inner parts of the resin gel (Mikhaylenko and Blokhin, 2012). 
The aim of this work was to study the phenomena related to recovery of $\operatorname{Re}$ from industrially relevant sulfate solutions in column operation with different kinds of weak anion exchangers. Sulfate and molybdenum concentrations were varied. Also batch kinetics experiments were done. Modeling of the process with appropriate equilibrium and mass transfer models, and speciation calculations, were done to obtain more information about the adsorption mechanism and phenomena involved. Elution is an important part of an ion exchange unit process, and especially with the Purolite A172 resin it is known to be complicated (Blokhin et al., 2011; Mal'tseva et al., 2012). It is discussed herein based on the available literature.

\section{Experimental}

All metal analyses of aqueous samples, both from batch and column experiments, were carried out from $10 \% \mathrm{HNO}_{3}$-media using inductively coupled plasma atomic emission spectroscopy (ICP-AES, device: IRIS Intrepid Duo, Thermo Electron Corporation).

\subsection{Materials and reagents}

Three weak anion exchangers (Table 1), which contain both gel-type and macroporous resins with different functional groups in them, were used. IRA-67 was supplied by Rohm\&Haas (currently Dow), and A172 and 170 by Purolite. The resins were preconditioned with two or three $\mathrm{H}_{2} \mathrm{SO}_{4}-\mathrm{H}_{2} \mathrm{O}-\mathrm{NaOH}-\mathrm{H}_{2} \mathrm{O}$ cycles, thus leaving them to free base form. The following chemicals were used in the experiments: $76 \% \mathrm{HReO}_{4}$ (supplier Aldrich), $\mathrm{MoO}_{3}$ (Merck), $\mathrm{Na}_{2} \mathrm{HAsO}_{4} \cdot 7 \mathrm{H}_{2} \mathrm{O}$ (Alfa Aesar), 95-97\% $\mathrm{H}_{2} \mathrm{SO}_{4}$ (Merck). 
Table 1. Characteristics of the weak anion exchange resins used in the experiments ("Amberlite IRA67 Product data sheet," 2008, "Purolite Products," 2014).

\begin{tabular}{llllll}
\hline Resin & Matrix & Functional group & Physical & Bed & $\boldsymbol{R}_{\mathbf{p}}, \boldsymbol{\mu m}$ \\
\hline IRA-67 & Acryl & Tertiary amine & Gel & $1.6 \mathrm{eq} / \mathrm{L}$ & $250-375$ \\
Purolite A170 & PS-DVB & Complex amine & Macroporous & $1.3 \mathrm{eq} / \mathrm{L}$ & $300-600$ \\
Purolite A172 & PS-DVB & Complex amine & Gel & $1.2 \mathrm{eq} / \mathrm{L}$ & $285 \pm 25$ \\
\hline
\end{tabular}

* Given by manufacturer

\subsection{Batch uptake kinetics experiments}

Batch uptake kinetics experiments were done at $25{ }^{\circ} \mathrm{C}$ with solutions containing either Re or Mo for IRA-67, Purolite A170 and A172 in $\mathrm{H}_{2} \mathrm{SO}_{4}$ concentration of $111 \mathrm{~g} / \mathrm{L}$ (measured by titration). In every experiment As $(c=916-993 \mathrm{mg} / \mathrm{L})$ was present to imitate the industrial solutions, but studying its kinetics was beyond the scope of this study. Before the actual experiment, the resin was preconditioned in pure $111 \mathrm{~g} / \mathrm{L} \mathrm{H}_{2} \mathrm{SO}_{4}$ to have it in protonated form. Initial Re and Mo concentrations, measured by ICP-AES, were respectively $55.5-57.2 \mathrm{mg} / \mathrm{L}$ and $2000-2040 \mathrm{mg} / \mathrm{L}$. Weighed resin amounts were $2.03 \mathrm{~g}$ for Re experiment with IRA-67, $4.04 \mathrm{~g}$ (Mo, IRA-67), $0.201 \mathrm{~g}$ (Re, A170), $4.00 \mathrm{~g}$ (Mo, A170), $0.203 \mathrm{~g}(\mathrm{Re}, \mathrm{A} 172)$, and $17.6 \mathrm{~g}$ (Mo, A172). Varying resin amounts were used in order to achieve sufficiently large changes in solution concentration relative to the accuracy of the chemical analyses. 


\section{$2.3 \quad$ Column experiments}

Dynamic column experiments were done in $15 \mathrm{~mm}$ diameter temperature controlled Kronlab columns at $25{ }^{\circ} \mathrm{C}$. Flowrate in every experiment was $2.0 \mathrm{~mL} / \mathrm{min}$ and the volume of the free base form resin bed was between 15.9 and $18.2 \mathrm{~mL}$ meaning 6.6-7.4 BV/h specific flow rates. In previous dynamic Re ion exchange studies for example 1.0 and 10 BV/h specific flow rates have been used (Blokhin et al., 2011; Mikhaylenko and Blokhin, 2012). The used flowrates are also typical for ion exchange studies generally and thus suitable for studying the phenomena in this work.

Metal and $\mathrm{H}_{2} \mathrm{SO}_{4}$ concentrations were chosen so that the solutions cover the most relevant industrial cases, which have been given for example by Mikhaylenko and Blokhin (2012). The $\mathrm{H}_{2} \mathrm{SO}_{4}$ concentrations may be as high as $500 \mathrm{~g} / \mathrm{L}$, but a moderate concentration of $100 \mathrm{~g} / \mathrm{L}$ was chosen for the higher showcase. In general the $\mathrm{H}_{2} \mathrm{SO}_{4}$ concentration is at least tens of $\mathrm{g} / \mathrm{L}$, and $\mathrm{pH}$ below 1 , so $15 \mathrm{~g} / \mathrm{L}$ was chosen to be the lower showcase. When Mo is present in industrial solutions, its concentration is usually at least several times higher than the Re concentration. Re concentration varies typically from few ppm up to grams per liter, and Mo concentration is in the level of grams per liter when it is present. Thus the Re concentration in the dynamic runs was set a bit above $100 \mathrm{mg} / \mathrm{L}$. Poor solubility of the used $\mathrm{MoO}_{3}$ gave some limitations to Mo concentration, however it was at least $812 \mathrm{mg} / \mathrm{L}$ in all cases, which is still in the range of the industrial cases. Runs without Mo were also performed, because solutions without Mo are also industrially used for Re recovery by ion exchange, like in KGHM Ecoren S.A., Poland (Chmielarz et al., 2010). Arsenic is often present in the industrially relevant solutions with typical concentration of few grams per liter, and thus As concentration in the dynamic runs was approximately $1000 \mathrm{mg} / \mathrm{L}$, except 
for the experiment A172 HS/2 (100 mg/L). Details of all experiments are given in Table 2. Elution of the resin beds were done with 1.0-1.5 M NaOH (specific flowrate 3.5-7.5 BV/h) to check the mass balances. Eluate was collected to one sample, and thus concentration profiles during elution were not recorded.

Dynamic adsorption capacities were calculated with the following expression:

$m_{\mathrm{ads}, \mathrm{k}}=\sum_{\mathrm{i}=1}^{\mathrm{N}} 0.5\left(\left(c_{\mathrm{k}}^{\text {feed }}-c_{\mathrm{k}, \mathrm{i}}\right)+\left(c_{\mathrm{k}}^{\text {feed }}-c_{\mathrm{k}, \mathrm{i}-1}\right)\right)\left(V_{\mathrm{i}}-V_{\mathrm{i}-1}\right)-\varepsilon_{\mathrm{b}} V_{\mathrm{bed}} c_{\mathrm{k}}^{\text {feed }}$

, where $m_{\text {ads }}$ is the adsorbed amount, $N$ stands for the number of sampling points, $c^{\text {feed }}$ is the feed concentration of metal $k, i$ is the index of the sampling point, $V$ is the eluted volume, and $\varepsilon_{\mathrm{b}}$ is the void fraction of the bed. The void fractions of the resin beds were calculated from column volume and mass of dry resin used to pack the column. The moisture contents of the swollen resins were measured, and were $0.430,0.395$ and 0.370 for IRA-67, Purolite A170 and A172 respectively. Porosity of the only macroporous resin Purolite A170 was calculated to be 0.352 from the experimentally determined moisture content. 
Table 2. Details of the breakthrough experiments for studying recovery of Re from sulfate solutions by weak anion exchangers. Fed amounts were $720 \mathrm{~mL}$ except for A170 HS (690 mL) and A172 HS/2 (13200 mL).

\begin{tabular}{|c|c|c|c|c|c|c|c|}
\hline Run ID & Resin & $c_{\mathrm{H} 2 \mathrm{SO} 4}, \mathrm{~g} / \mathrm{L}$ & $c_{\text {Re }}, \mathrm{mg} / \mathrm{L}$ & $c_{\mathrm{Mo}}, \mathrm{mg} / \mathrm{L}$ & $c_{\mathrm{As}}, \mathrm{mg} / \mathrm{L}$ & $V_{\text {bed }}, \mathbf{m L}$ & BV/h \\
\hline IRA HS & IRA-67 & 100 & 100 & 994 & 961 & 18.2 & 6.6 \\
\hline A170 HS & Purolite A170 & 100 & 117 & 2024 & 1011 & 17.3 & 6.9 \\
\hline A172 HS/1 & Purolite A172 & 100 & 120 & 2024 & 1020 & 16.3 & 7.4 \\
\hline A172 HS/2 & Purolite A172 & 100 & 137 & 2332 & 100 & 16.8 & 7.1 \\
\hline IRA LS & IRA-67 & 15 & 123 & 812 & 997 & 18.2 & 6.6 \\
\hline A170 LS & Purolite A170 & 15 & 123 & 812 & 997 & 17.3 & 6.9 \\
\hline A172 LS & Purolite A172 & 15 & 125 & 817 & 1014 & 16.3 & 7.4 \\
\hline IRA NM & IRA-67 & 100 & 118 & - & 1063 & 18.2 & 6.6 \\
\hline A170 NM & Purolite A170 & 100 & 119 & - & 1045 & 17.3 & 6.9 \\
\hline A172 NM & Purolite A172 & 100 & 120 & - & 1077 & 16.3 & 7.4 \\
\hline
\end{tabular}




\section{3. $\quad$ Modeling}

Modeling and simulation of batch uptake kinetics and adsorption column dynamics was done in order to obtain a better understanding about the mechanisms and the phenomena related to the adsorption of $\operatorname{Re}$ and the impurities from the industrially relevant sulfate solutions. Though there has been discussion about these topics in the literature, there seems not to be unanimous agreement.

\subsection{Model development}

Competitive uptake of rhenium, molybdenum and arsenic from sulfuric acid solutions is considered here as competitive adsorption of oxyacids (protonation+oxyanion) on baseform resins. For simplicity the adsorption of Re, Mo and sulfates are described in the model with a single equilibrium constant for each. $\mathrm{ReO}_{4}^{-}$has been evidently taken as representative for Re. $\mathrm{HSO}_{4}^{-}$is taken as representative of a sulfate species, although as

discussed in more detail later, part of it is as $\mathrm{SO}_{4}{ }^{2-}$ form even in higher acidities. Due to very complex speciation chemistry of Mo, which is also discussed later in detail, just the chemical symbol is used. Adsorption equilibrium is described using the competitive Langmuir isotherm. Mass transfer in the resin particles is modeled using the concentrationlayer model of Yao and Tien (1993). This model was selected, because it gives much better description at low loadings than the conventional linear driving force (LDF) approximation. Because the concentrations are not extremely low, the external mass transfer resistance is neglected to simplify the numerical solution. 
Experiments were made in batch and fixed-bed systems and the mass balances are given in Eqs. (2) and (3), where $c$ is the solution concentration, $\bar{q}$ is volume-averaged concentration in the resin, $V_{\mathrm{L}}$ is liquid volume, $V_{\mathrm{S}}$ is resin volume, $v$ is interstitial flow velocity, $t$ is time, $x$ is the axial coordinate, $\varepsilon_{\mathrm{b}}$ is bed porosity, $\rho_{\mathrm{s}}$ is resin density and $D_{\mathrm{ax}}$ is axial dispersion coefficient. Variation of the resin volume is not considered here and thus $\varepsilon_{\mathrm{b}}$ is constant.

$V_{L} \frac{\partial c_{i}}{\partial t}+V_{S} \frac{\partial \bar{q}_{i}}{\partial t}=0$

$$
\frac{\partial c_{i}}{\partial t}+v \frac{\partial c_{i}}{\partial x}+\left(\frac{1-\varepsilon_{b}}{\varepsilon_{b}}\right) \frac{\partial \bar{q}_{i}}{\partial t}-D_{a x} \frac{\partial^{2} c_{i}}{\partial x^{2}}=0
$$

The accumulation terms $\partial \overline{q_{\mathrm{i}}} / \partial t$ and $\overline{\partial \bar{c}_{p, i}} / \partial t$ are obtained from the model of Yao and Tien (1993). In gel-type resins (Eq. (4a)), mass transfer is described by the apparent diffusion coefficient, $D_{\mathrm{s}}$, in the swollen gel. For macroporous resins, intra-particle mass transfer is assumed to be controlled by pore diffusion characterized by $D_{\mathrm{p}}$ (Eq. (4b)).

$$
\begin{aligned}
& \frac{\partial \bar{q}_{i}}{\partial t}=\frac{24 D_{s, i}}{d_{s}^{2}}\left(\frac{q_{i}^{*}}{\bar{q}_{i}}+\frac{1}{2}+\frac{\bar{q}_{i}}{q_{i}^{*}}\right)\left(q_{i}^{*}-\bar{q}\right) \\
& \frac{\partial \overline{c_{p, i}}}{\partial t}=\frac{24 \varepsilon_{p} D_{p, i}}{d_{p}^{2}}\left(\frac{c_{p, i}^{*}}{\overline{c_{p, i}}}+\frac{1}{2}+\frac{\overline{c_{p, i}}}{c_{p, i}^{*}}\right)\left(c_{p, i}^{*}-\overline{c_{p, i}}\right)
\end{aligned}
$$

The equilibrium condition for competitive adsorption of several acids (competitive Langmuir) is given by Eq. (5), which relates the concentration on the resin surface to the 
solution concentration. If macroporous resins are considered, same expression is assumed valid but average pore solution concentration, $\bar{c}_{p}$, and uptake, $\bar{q}$, are used.

$q_{i}^{*}=Q_{\max } \frac{K_{i} c_{i}}{1+\sum_{j}\left(K_{j} c_{j}\right)}$

In Eq. (5), $Q_{\max }$ is the adsorption capacity determined by the number of amino groups. Values calculated from the manufacturer given bed capacities (Table 1) were used (IRA$67=5.10 \mathrm{eq} / \mathrm{kg}, \quad$ Purolite A170 = $3.16 \mathrm{eq} / \mathrm{kg}, \quad$ Purolite A172 = $2.29 \mathrm{eq} / \mathrm{kg}$ ), and before calculations converted to units of eq/L since the solid contents in swollen resins were measured. $K$ is the affinity constant.

\subsection{Calculations}

The differential mass balances were solved using the method of lines (Schiesser, 1991). Initial and boundary conditions for the column are given by Eq. (6). Here $c^{0}$ is the concentration in solution used to pre-treat the resin and $q^{0}$ is the corresponding value in the resin calculated from Eq. (5).

$$
\begin{aligned}
t=0: & c_{i}(x)= \\
q_{i}(x)= & q_{i}^{0} \\
t>0: & \left.\frac{\partial c_{i}}{\partial x}\right|_{x=0}=-\frac{v}{D_{a x}}\left(c_{i}^{\text {feed }}-c_{i}(x=0)\right)
\end{aligned}
$$

Value for the axial dispersion coefficient was estimated from the correlation of Chung and Wen (1968) and same value was used for all components. 


\section{Results and discussion}

Before discussing the selectivities of the resins, the validity of the main experimental method and accuracy of the chemical analyses are briefly addressed. Table 3 displays the amounts of Re sorbed by the resins obtained by two different methods: the loading data (breakthrough experiments and Eq. (1)) and $\mathrm{NaOH}$ elution data. The values differ by only $2-7 \%$, except for experiment IRA NM where the deviation was $18 \%$. This is seen as an evidence of reliable Re ICP analysis. The larger difference with the experiment IRA NM stems from the fact that in the loading experiment the feed concentration was achieved already after the $4^{\text {th }}$ sampling point, and thus the shape of the breakthrough curve is not accurately recorded. With Mo and As, however, inaccuracy in analysis was higher and the uptakes calculated with Eq. (1) are shown only for Re. The Mo and As uptake values obtained by the $\mathrm{NaOH}$ elution method are expected to be more accurate, and thus they have been used for calculating the selectivities and purities in Table 3. Despite the known fact that $\mathrm{Re}$ is not easily eluted especially from the Purolite A172 (Blokhin et al., 2011; Mal'tseva et al., 2012), the results in Table 3 show the elution method used here removed all the adsorbed metals well and the obtained uptake values can be used as a basis for the following discussion.

\section{$4.1 \mathrm{ReO}_{4}{ }^{-} / \mathrm{SO}_{4}{ }^{2-}$ and $\mathrm{ReO}_{4}{ }^{-} / \mathrm{HSO}_{4}^{-}{ }^{-}$-selectivities}

According to the conventional knowledge about the dissociation chemistry of the $\mathrm{H}_{2} \mathrm{SO}_{4}$ there should not be much $\mathrm{SO}_{4}{ }^{2-}$ present in the $15 \mathrm{~g} / \mathrm{L} \mathrm{H}_{2} \mathrm{SO}_{4}$ and practically none in the $100 \mathrm{~g} / \mathrm{L}$ concentration, and the dominating specie should be $\mathrm{HSO}_{4}{ }^{-}$. However, when the 
speciation is calculated taking into account non-idealities of the solutions with Davies' and Pitzer's models it is observed that the $\mathrm{SO}_{4}{ }^{2-}$ concentration does not decrease below ca. $19 \%$ even in $200 \mathrm{~g} / \mathrm{L}$ acidity (Casas et al., 2000). Also due to protonation of the resin and the resulting Donnan exclusion it can be predicted that proton concentration inside especially the gel-type resins would be lower than in the bulk solution. Thus in this section the $\mathrm{Re}$ selectivity is discussed in relation to both $\mathrm{SO}_{4}{ }^{2-}$ and $\mathrm{HSO}_{4}{ }^{-}$.

Despite the differences in the Re capacities of the resins, all of them are able to take it from concentrated sulfate solutions (Table 3). Also the fitted parameters in the equilibrium model (Table 4) support this conclusion; with all the modeled resins the affinity constant $K$ is higher for $\mathrm{HReO}_{4}$ than for $\mathrm{HHSO}_{4}$. According to Blokhin et al. (2005), anion exchange selectivities can be explained by the size and, most importantly, hydration tendencies of the anions so that the less hydrated ions have higher affinities. Gibbs free energies of hydration at $25{ }^{\circ} \mathrm{C}$ are $-226,-330$ and $-975 \mathrm{~kJ} / \mathrm{mol}$ for $\mathrm{ReO}_{4}{ }^{-}, \mathrm{HSO}_{4}{ }^{-}$and $\mathrm{SO}_{4}{ }^{2-}$ respectively (Marcus, 2015) thus indicating weaker hydration tendency of the $\mathrm{ReO}_{4}{ }^{-}$than the sulfate species, especially $\mathrm{SO}_{4}{ }^{2-}$. The radii of the corresponding ions are $0.26,0.19$ and $0.23 \mathrm{~nm}$ (Marcus, 2015), and based on these and the Gibbs free energies of hydration it can be inferred that the sizes of the hydrated anions have the order $\mathrm{SO}_{4}{ }^{2-}>\mathrm{HSO}_{4}^{-}>\mathrm{ReO}_{4}^{-}$. Such thermodynamic properties give basis for the wide and successful use of anion exchange resins for the recovery of Re from sulfuric acid solutions. 
Table 3. Metal contents in the resin beds after Re recovery experiments from sulfate solutions (presented in Table 2) with weak anion exchangers.

\begin{tabular}{|c|c|c|c|c|c|c|c|c|c|c|c|}
\hline Run ID & $q^{\prime}$ Re,load, & $q^{\prime}$ Re,elu, & mass & $q^{\prime} \mathrm{Mo}$, & elu, & $q_{\text {As, }}^{\prime}$ & elu, & $q^{\prime}$ Re,sim, & $q_{\text {Re,sim }}^{\prime} / q^{\prime}$ Mo & $q_{\text {Re,sim }}^{\prime} / q_{\text {As }}^{\prime}$ & $q^{\prime}{ }_{\text {Re,sim }} / q^{\prime}$ total \\
\hline IRA HS & 0.60 & NA & NA & NA & & NA & & 0.4 & $0.02 *$ & $0.15^{*}$ & $0.02 *$ \\
\hline A170 HS & 4.6 & 4.5 & $2.2 \%$ & 23.9 & & 2.1 & & 36.0 & 1.5 & 17.1 & 0.58 \\
\hline A172 HS/1 & 5.3 & 5.0 & $5.7 \%$ & 0.9 & & 1.6 & & 85.8 & 95.3 & 53.6 & 0.97 \\
\hline IRA LS & 1.5 & 1.4 & $6.7 \%$ & 28.3 & & 6.1 & & 1.6 & 0.06 & 0.26 & 0.04 \\
\hline A170 LS & 4.7 & 5.0 & $-6.0 \%$ & 14.8 & & 1.7 & & 78.4 & 5.3 & 46.1 & 0.83 \\
\hline A172 LS & 5.5 & 5.2 & $5.5 \%$ & 0.19 & & 0.07 & & 166 & 867 & 2550 & 1.00 \\
\hline IRA NM & 0.64 & 0.78 & $-18 \%$ & - & & 0.77 & & 0.58 & - & 0.75 & 0.43 \\
\hline A170 NM & 4.9 & 4.9 & $0 \%$ & - & & 1.44 & & 97.2 & - & 67.5 & 0.99 \\
\hline A172 NM & 5.3 & 5.1 & $3.8 \%$ & - & & 1.36 & & 94.0 & - & 69.1 & 0.99 \\
\hline
\end{tabular}

* Calculated from breakthrough curves since elution data was not available. NA = not available.

** Simulated Re intakes $q$ 'Re,sim have been used to calculate selectivities and purity because no full breakthrough was obtained for every experiment. Subscript load stands for the value calculated from the measured breakthrough curve by Eq. 1. These values have not been presented for Mo and As because their analysis in low concentrations had too much variance causing inaccuracy in the calculated values. Subscript $e l u$ stands for the values obtained by eluting the bed with $\mathrm{NaOH}$ as described in the section 2.3. 
Table 4. Model (see section 3.1) parameters for adsorption of Re and Mo from sulfate solutions. $T=25{ }^{\circ} \mathrm{C}$. The anion exchange is modeled as a competitive adsorption of acids of the corresponding anions (see section 3.1). External mass transfer was neglected.

\begin{tabular}{lllllll}
\hline & IRA-67 & & \multicolumn{2}{l}{ Purolite A170 } & \multicolumn{2}{l}{ Purolite A172 } \\
& $\log \boldsymbol{K}$ & $\boldsymbol{D}_{\mathbf{s}}$ & $\log \boldsymbol{K}$ & $\boldsymbol{D}_{\mathbf{p}}$ & $\log \boldsymbol{K}$ & $\boldsymbol{D}_{\mathbf{s}}$ \\
\hline $\mathrm{HHSO}_{4}$ & 5.0 & $1.00 \cdot 10^{-11}$ & 3.0 & $1.00 \cdot 10^{-10}$ & 3.0 & $1.00 \cdot 10^{-13}$ \\
$\mathrm{HReO}_{4}$ & 5.5 & $1.00 \cdot 10^{-11}$ & 6.1 & $1.94 \cdot 10^{-10}$ & 6.1 & $5.00 \cdot 10^{-14}$ \\
$\mathrm{HMo}$ & 6.3 & $2.85 \cdot 10^{-12}$ & 4.9 & $5.99 \cdot 10^{-11}$ & 3.7 & $1.00 \cdot 10^{-14}$ \\
\hline
\end{tabular}

Purolite A172 and A170 resins had clearly better Re adsorption capacities than the IRA67 for all the studied feed solutions (Table 3). This has to be related to the similar functional group of the Purolite resins (complex amine according to the manufacturer), since breakthroughs occurred much earlier with the IRA-67 resin having tertiary amine functionality (Fig. 1) but similar gel-type physical structure as A172. In addition, the Purolite A170 resin has macroporous physical structure, but it still had the previously mentioned high Re capacity. All the resins had clearly higher capacities in $15 \mathrm{~g} / \mathrm{L} \mathrm{H}_{2} \mathrm{SO}_{4}$ concentration than in $100 \mathrm{~g} / \mathrm{L}$ concentration (Table 3 ). In addition to the obvious competing effect, the decreasing $\mathrm{Re}$ uptake in higher $\mathrm{H}_{2} \mathrm{SO}_{4}$ concentrations has been explained by Blokhin et al. (2005) with so-called acid effect meaning that in the higher acidity there is more $\mathrm{HSO}_{4}{ }^{-}$, which has higher affinity to the anion exchangers due to its weaker hydration. Also in a recent review paper by Srivastava et al. (2015) it is stated that the $\mathrm{HReO}_{4}$ would not be totally dissociated in acid concentrations higher than $0.5 \mathrm{M}$, which is another factor for the lowering Re uptakes with increasing acidities. 

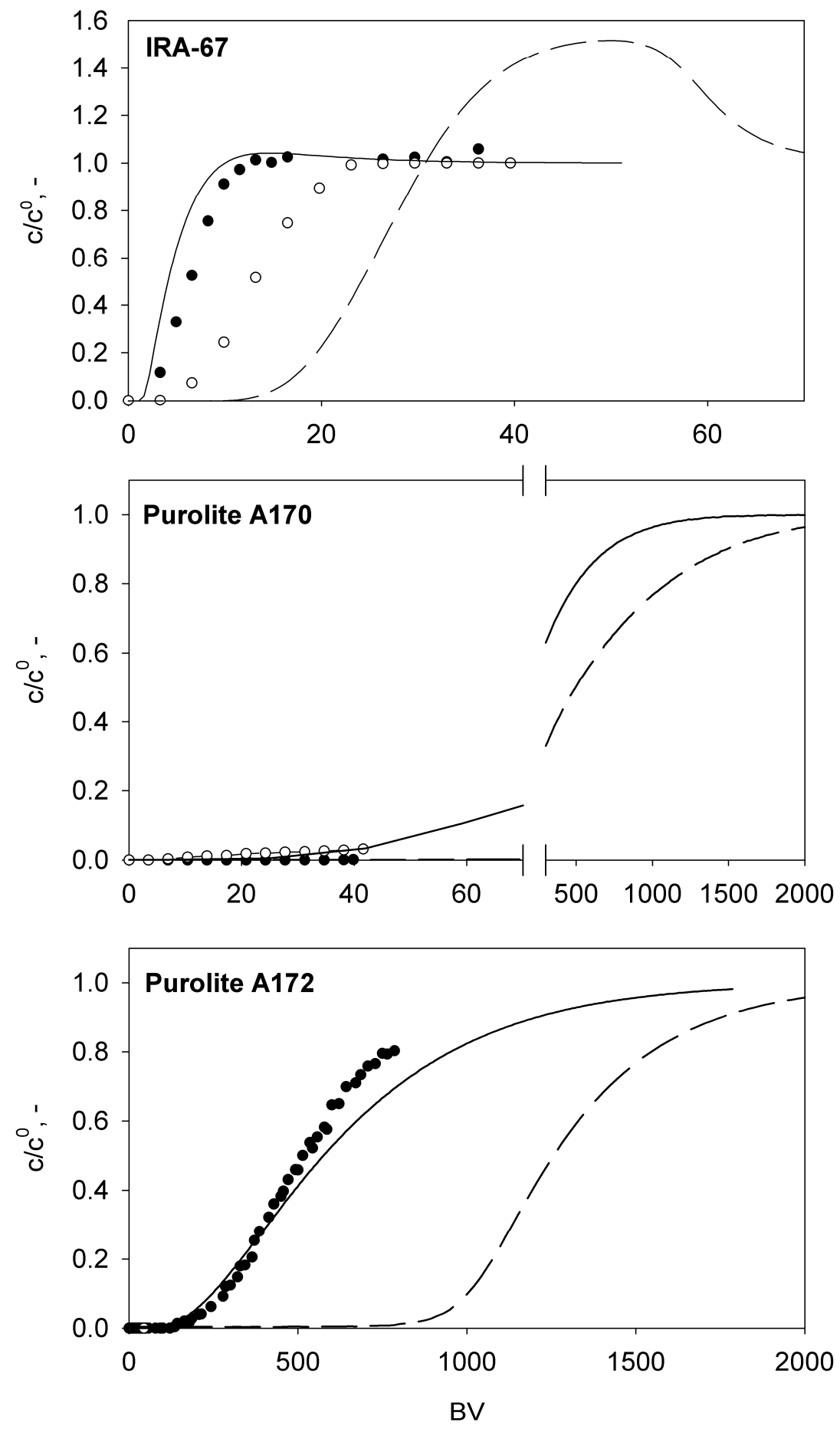

Figure 1. Measured (symbols) and simulated (lines) breakthrough curves of Re with weak anion exchangers from $\mathrm{H}_{2} \mathrm{SO}_{4}$ solutions. Filled symbols and solid lines $100 \mathrm{~g} / \mathrm{L} \mathrm{H}_{2} \mathrm{SO}_{4}$, open symbols and dashed lines $15 \mathrm{~g} / \mathrm{L} \mathrm{H}_{2} \mathrm{SO}_{4}$. Analyses of feed solutions are presented in Table $2 . T=25^{\circ} \mathrm{C}$. 
The conclusions above about the $\mathrm{ReO}_{4}{ }^{-} / \mathrm{SO}_{4}{ }^{2-}$ and $\mathrm{Re} / \mathrm{HSO}_{4}{ }^{-}$-selectivities are supported by the fitted model parameters shown in Table 4. The fitting was first done on the batch uptake curves measured for individual Re and Mo solutions without competition (Fig. 2), but some parameter adjustment was needed to correlate data from dynamic column experiments (Figs. 1, 3 and 5) as well as possible. As stated in the section 2.2, the kinetics of As was not studied here, though it was present in the solutions to imitate the industrial Re solutions. Generally the model presented in Eqs. (2-5) predicts the batch uptake kinetics well. The affinity constants $K$ of $\mathrm{HReO}_{4}$ to the Purolite resins are higher than for the IRA-67, and also the values of $\mathrm{HHSO}_{4}$ are lower. The fact that the ratio of the affinity constants of $\mathrm{HReO}_{4}$ and $\mathrm{HHSO}_{4}$ (i.e., =selectivity) for IRA-67 is much lower than for the Purolite resins explains also the observation that the acid concentration has much more influence on the Re adsorption with the IRA-67. 


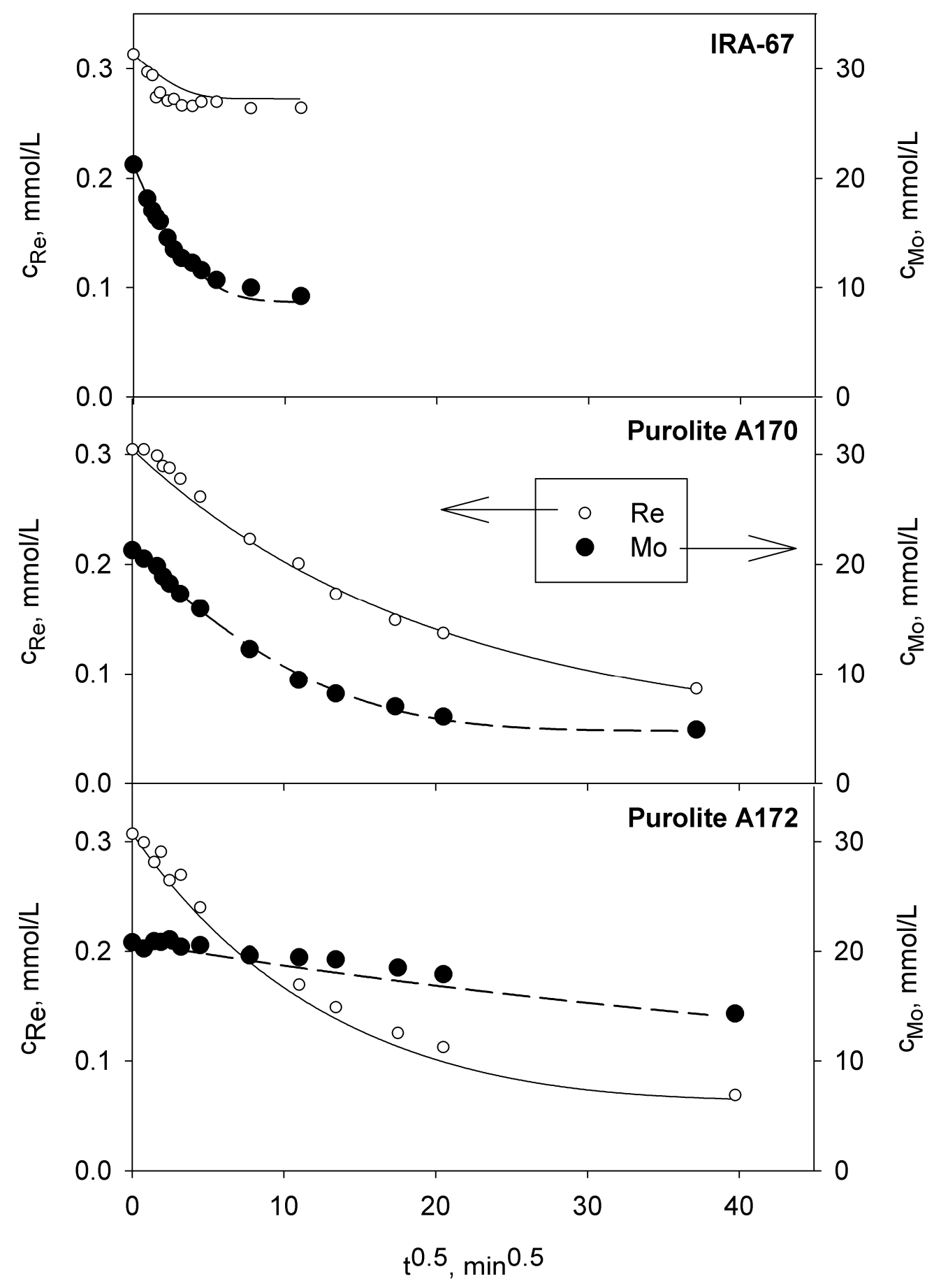

Figure 2. Batch uptake kinetics of recovery of Re and Mo from sulfate solutions with weak anion exchangers. $T=25^{\circ} \mathrm{C}$. Separate experiments were made for Re and Mo uptake kinetics. The phase ratios varied between the six experiments and have been given in Section 2.2 as well the exact initial concentrations. 


\subsection{Re/Mo and Re/As-selectivities}

Physical structure of anion exchanger has a significant role in Re/Mo selectivity. This can be clearly seen by comparing the ratios of adsorbed amounts of these metals and the breakthrough curves with the Purolite resins A170 and A172 with similar functional groups (Table 3, Figs. 1 and 3). This is in accordance with results of Kholmogorov et al. (1999), who concluded that in their studies all the resins with good Re/Mo selectivity were geltype. The gel-type A172 has very high Re/Mo selectivity compared to the macroporous A170. In fact in all column experiments with the IRA-67 and Purolite A170 and feed solutions containing Mo, the absolute amount of adsorbed Re was less than that of Mo, though all these experiments were not run until Re breakthrough. Obviously though, the gel-type physical structure does not alone explain the selectivity because it was poor with the other gel-type resin IRA-67. 

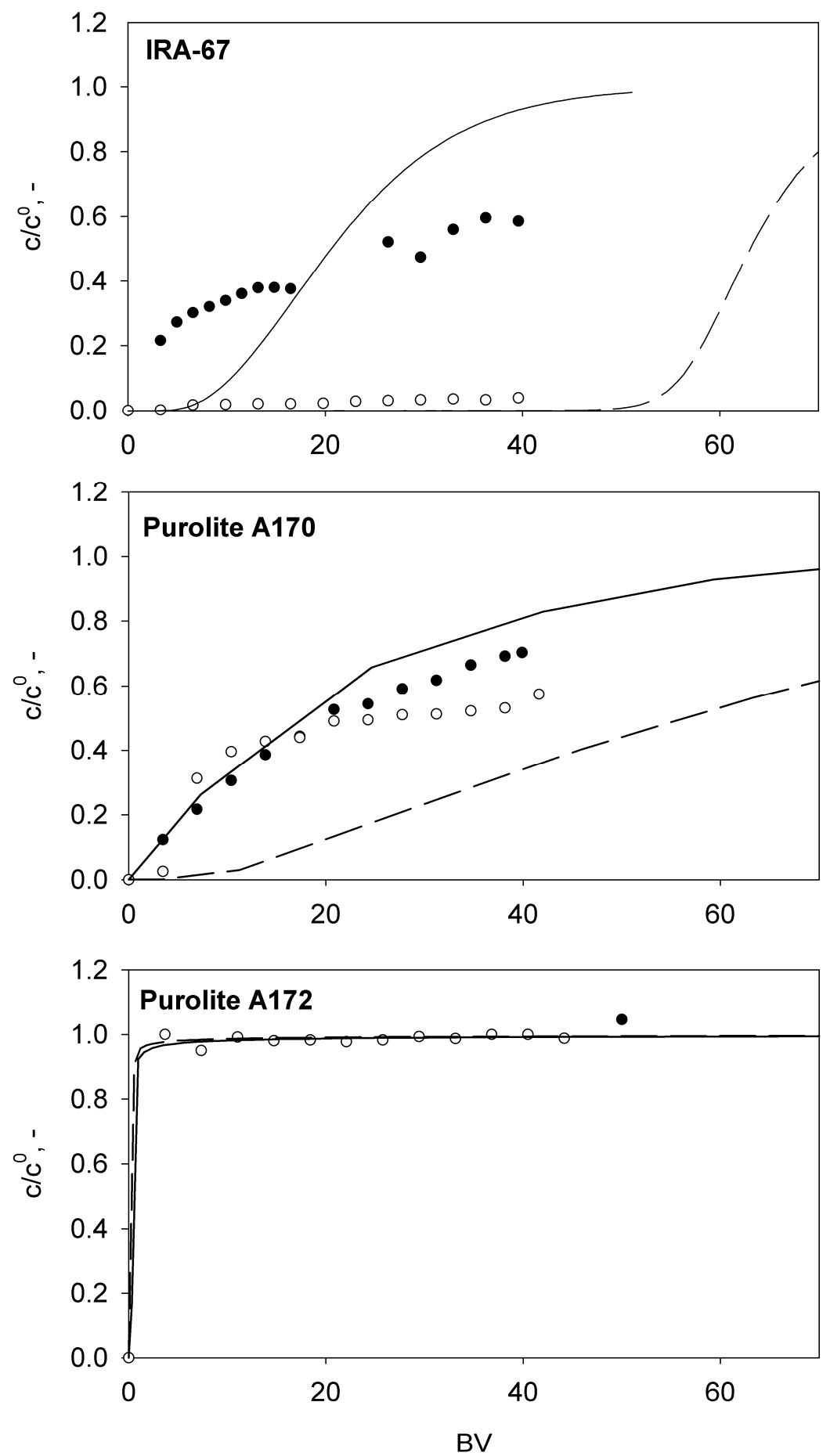

Figure 3. Measured (symbols) and simulated (lines) breakthrough curves of Mo with weak anion exchangers from $\mathrm{H}_{2} \mathrm{SO}_{4}$ solutions. Filled symbols and solid lines $100 \mathrm{~g} / \mathrm{L} \mathrm{H}_{2} \mathrm{SO}_{4}$, open symbols and dashed lines $15 \mathrm{~g} / \mathrm{L} \mathrm{H}_{2} \mathrm{SO}_{4}$. Analyses of feed solutions are presented in Table $2 . T=25^{\circ} \mathrm{C}$. 
The model parameters (Table 4) estimated from the experimental data indicate that the nature of the resins' Re/Mo selectivities can be explained by the equilibrium behavior. However, simply the affinities of the metals to the functional groups do not alone explain the selectivities. This can be concluded from the modeled breakthrough curves in Figs. 1 and 3, which did not match the experimental data in every case though the diffusion coefficients were tried to adjust to give better fits. The different physical structures of the resins can affect the migration speeds of the oxyanion species, and it is also possible that for example large Mo species can only be sorbed to the sites on the surface either in gel or macropores at sufficiently high rate for significant binding. The speciation of the metals in the system differ quite a lot, and it depends on the concentration of the metals and acidity $(\mathrm{pH})$ both in the bulk solution and inside the resin. The effects of all of these phenomena are discussed in detail below.

Diffusion coefficients of $\mathrm{HReO}_{4}$ and $\mathrm{HMo}$ in the Purolite A172 are several orders of magnitude smaller than those in IRA-67 (Table 4), which is of gel-type also. This supports the suggestion of Mikhaylenko and Blokhin (2012) about the steric phenomena being the explanation to the Re/Mo selectivity. The gel structure in the A172 might be so dense that it hinders the migration of the oxyanions to the resin. To support this conclusion the moisture contents of the resins were measured in $110 \mathrm{~g} / \mathrm{L} \mathrm{H}_{2} \mathrm{SO}_{4}$ and they were $48.4,35.6$ and 22.8\% respectively for IRA-67, Purolite A170 and A172. Diffusion coefficient of HMo in Purolite A172 is also five times smaller than that of $\mathrm{HReO}_{4}$, but still the difference is not enough to explain the Re/Mo selectivity with kinetics. Thus the explanation must be equilibrium based: Mo species have ability entering only near to the surface of the resin gel area, which is seen as the low affinity parameter $K$ in the competitive Langmuir 
equilibrium model. In that case the Mo capacity would depend on the surface area, which in gel-type resin is very small compared to macroporous resin.

The gradual breakthrough curves of Mo with IRA-67 and Purolite A170 resins (Fig. 3) suggests that the kinetics of Mo would be slow, but the fitted diffusion coefficients were of the same magnitude as for the other compounds. Such gradual Mo breakthrough curves can result from the complex speciation of Mo illustrated in Fig. 4. Mo exists as several different oxyanions, and the basis is on molybdic acid $\mathrm{H}_{2} \mathrm{MoO}_{4}$ and its dissociation and protonation equilibria. At $\mathrm{H}^{+}$concentrations between $10^{-5}$ and $10^{-1} \mathrm{~mol} / \mathrm{L}$ also different polynuclear complexes exist. Gibbs free energy of hydration for $\mathrm{MoO}_{4}{ }^{2-}$ is $-964 \mathrm{~kJ} / \mathrm{mol}$ (Dudev and Lim, 2004), and thus the hydrated anion is expected to be larger than $\mathrm{ReO}_{4}^{-}$, and consequently the polymeric oxyanions probably are much larger than $\mathrm{ReO}_{4}^{-}$. This might lead to stronger size exclusion of Mo in the gel-type Purolite A172, because due to Donnan exclusion proton concentration is supposed to be lower inside the gel than in the macropores of the A170 (Helfferich, 1995).

The free proton concentration in solution, which is not equal to stoichiometric sulfuric acid concentration, was calculated with computer program (KTH - Chemistry / Chemical Equilibrium Diagrams, n.d.) for $960 \mathrm{mg} / \mathrm{L}$ Mo solutions in sulfuric acid concentrations of $15 \mathrm{~g} / \mathrm{L}$ and $100 \mathrm{~g} / \mathrm{L}$. The results $(\mathrm{as}[\mathrm{H}+])$ were $0.12 \mathrm{M}$ and $0.82 \mathrm{M}$, respectively. This means that there would be only a small amount of anionic Mo-species at the lower sulfuric acid concentration and practically none at the higher acid concentration. However, as stated by Mikhaylenko and Blokhin (2012), occurrence of anionic sulfate complexes of Mo, like $\mathrm{MoO}_{2}\left(\mathrm{SO}_{4}\right)_{2}{ }^{2-}$ has also been observed in high sulfuric acid concentrations. Based on the 
above discussion with the fact that the acidity is lower inside the gel-type resin particle, it is possible that in the both studied feed solutions there are anionic Mo species present, especially inside the gel-type resins. On the other hand, the speciation shown in Fig. 4 and the above discussion is limited only to Mo(VI) species but, according to for example Barret (2003), existence of mono- and polynuclear cationic Mo-species with different oxidation states is possible in acidic conditions.

Another possibility of Mo adsorption to the N-donor type weak anion exchangers, which all of the resins studied in this research are, is chelation of the cationic Mo species. These include the ones shown in the Fig. 4 (the equilibria calculated based on the equilibria suggested by Olazabal et al. (1992)), the well-known $\mathrm{MoO}_{2}{ }^{2+}$ and the possible cations with lower Mo oxidation states. Although being not very abundant, some species where Mo is coordinated to N-atom have been mentioned (Cotton and Wilkinson, 1988; Holm et al., 1996). However, if the secondary amine functional group of the Purolite resins would have the feature of the chelate formation, the mechanism could not likely be the same with the conventional tertiary amine functional IRA-67. As shown for example in Table 3, it has a high affinity towards the Mo. Thus this explanation with formation of the chelates would mean different Mo binding mechanisms to the macroporous Purolite A170 (chelation), and the gel-type Purolite A172 and IRA-67 (anion exchange in lower acidity inside the resin). In that case the exclusion of Mo from the Purolite A172 would still be due to the steric effects discussed before in this section. It should be though added to the above discussion that $\mathrm{N}$-donor type ligands are known to have very high proton affinities, and thus for example the cations of transition metals are not practically sorbed to them at $\mathrm{pH}$ below 3 (Laatikainen et al., 2007). 
The easier diffusion of the smaller hydrated $\mathrm{ReO}_{4}{ }^{-}$anion inside the resin particle has been stated to be the reason for Purolite A172's good Re/Mo selectivity also by (Mikhaylenko and Blokhin, 2012). The complex Mo speciation is probably also the reason that the model predicts too late breakthrough for Re with IRA-67 from $15 \mathrm{~g} / \mathrm{L} \mathrm{H}_{2} \mathrm{SO}_{4}$ solution (Fig. 1). However, despite the supposed significant effect of the speciation, it was not included to the equilibrium model, because the purpose of the modeling was only to help with discussing the nature of the $\mathrm{Re} / \mathrm{SO}_{4}{ }^{2-}, \mathrm{Re} / \mathrm{HSO}_{4}{ }^{-}$and $\mathrm{Re} / \mathrm{Mo}$ selectivities and not to predict accurately the behavior of the all components in all systems. 


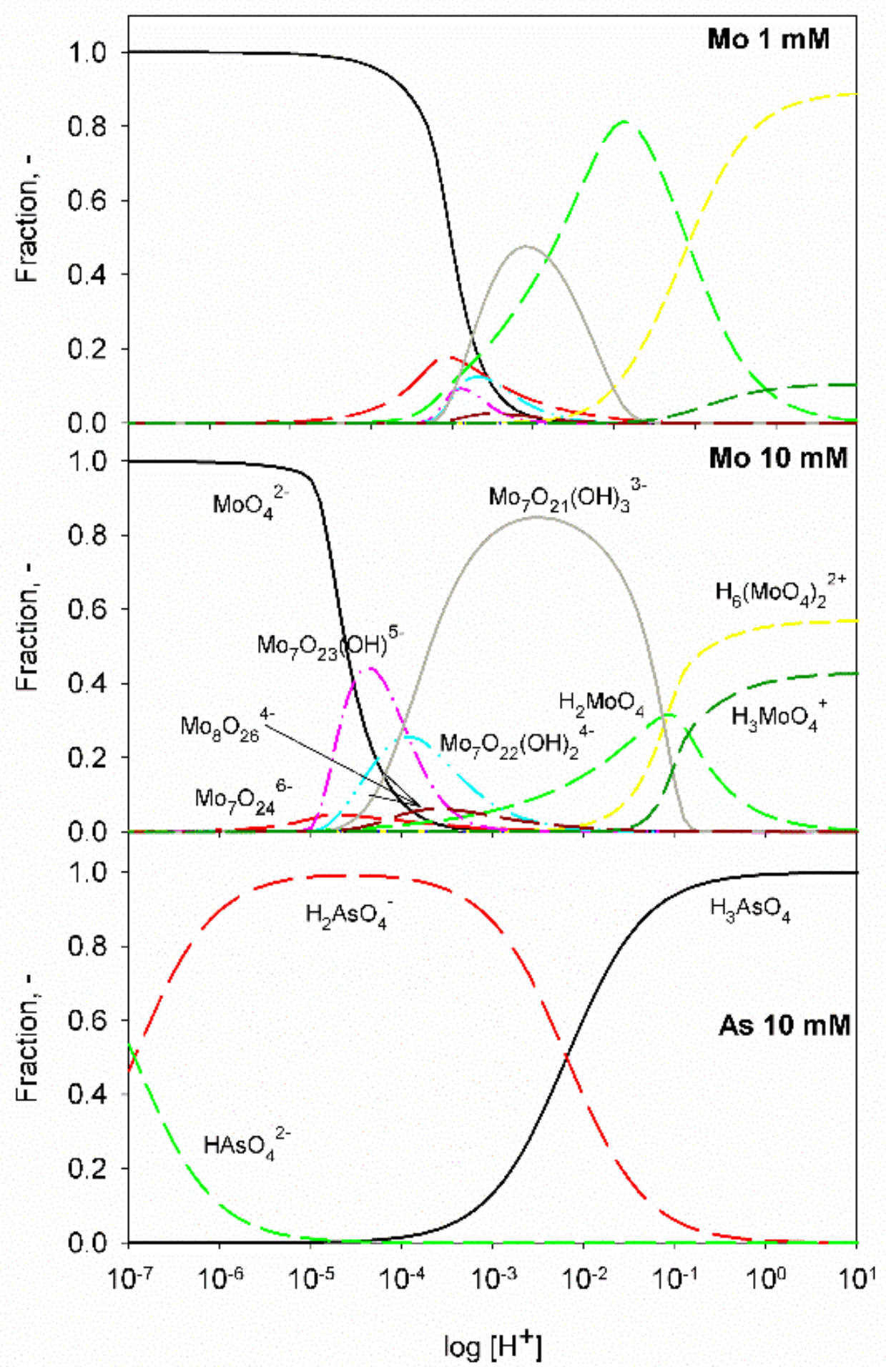

Figure 4. Speciations of $\mathrm{Mo}(\mathrm{VI})$ and $\mathrm{As}(\mathrm{V})$ as a function proton concentration. Values for formation constants of the Mo(VI) species have been taken from (Olazabal et al., 1992) and As(V) species from (Wroński, 1997). 
The breakthroughs for As in every experiment occurred almost immediately, and there were no differences in the curves between the resins. Thus the curves are not shown and the behavior of As was not included in the model. Arsenic exists as arsenic acid, $\mathrm{H}_{3} \mathrm{AsO}_{4}$ $\left(\mathrm{p} K_{\mathrm{a} 1}=2.19, \mathrm{p} K_{\mathrm{a} 2}=6.94\right)$, and its dissociation products (Fig. 4). The hydrated forms of these species are even larger than $\mathrm{SO}_{4}{ }^{2-}$ (Tanaka et al., 2013) thus explaining good selectivities of $\operatorname{Re}$ (and Mo) over As for the reasons discussed before. However, there were significant differences, especially in the lower $\mathrm{H}_{2} \mathrm{SO}_{4}$ concentration $(15 \mathrm{~g} / \mathrm{L})$, between the resins' in the Re/As selectivity. The Purolite resins were again better than the IRA-67, and they did not have significant difference. A remarkable observation also was that Mo and As capacities of both Purolite resins increased with increasing $\mathrm{H}_{2} \mathrm{SO}_{4}$ concentration (Table 3). This can be explained by the speciation chemistry, i.e. more abundant occurrence of more hydrophobic (and smaller) ions, which again have higher affinity to the functional group.

From the above discussion it can be concluded that the complex amine functional group in the Purolite resins favor more hydrophobic and univalent anions, whereas the tertiary amine functional IRA-67 favors larger, multivalent and more hydrophilic anions causing its poor Re/Mo and Re/As selectivities. As discussed earlier in this section, Re is seen as more hydrophobic than all the other species in the studied solutions, and the multivalent anions like sulfate, dissociation products of arsenic acid, and polymeric oxyanions and sulfate complexes of Mo are seen as the most hydrophilic species. The physical structure of the resins and the speciation of the metals were also identified as significant phenomena affecting both the equilibria and kinetics of the metals' sorption. 


\subsection{Practical implications}

The Purolite resins, especially A172, were found to be superior for the recovery of Re from $\mathrm{SO}_{4}{ }^{2-}$ solutions among the three studied weak anion exchangers. The difference between the Purolite resins is that the A170 does not provide as good Re/Mo selectivity as A172 does. Good performance of the resins in high $\mathrm{H}_{2} \mathrm{SO}_{4}$ concentrations and high $\mathrm{Re} / \mathrm{Mo}$ selectivity are important because acidity and presence of Mo are characteristic for many industrial Re leachates (Mikhaylenko and Blokhin, 2012). In terms of Re/As selectivities the Purolite resins were also better implicating that the conventional weak anion exchangers, like IRA-67, do not probably function if there are any oxyanion forming metals in the feed. If the $\mathrm{H}_{2} \mathrm{SO}_{4}$ concentration is lower (15 g/L tested in this work) the uptake of the IRA-67 resin increases, but is still lower than the uptake of the Purolite resins. Also the $\mathrm{Re} / \mathrm{Mo}$ and $\mathrm{Re} / \mathrm{As}$ selectivities are still very low when the $\mathrm{H}_{2} \mathrm{SO}_{4}$ concentration decreases (Table 3).

The absence of Mo increases the dynamic Re capacity of Purolite A170 significantly but of A172 only slightly (Table 3, Fig. 5). The capacity of A170 is slightly higher (Table 3) because of the higher mass transfer rate (Table 4) and thus it might be even more suitable than A172 for separation of Re from As containing feed solutions in absence of Mo. On the other hand, if the recovery yield of Re must be very high, A172 would be a better choice, because the breakthrough occurs earlier with the A170 (Fig. 5). Also with IRA-67 the Re breakthrough capacity (Table 3) slightly improved in absence of Mo. One such Re solution that contains As as the main impurity is typical washing acid from a $\mathrm{Cu}$ smelter. For example, KGHM Ecoren S.A. operates such a Re recovery plant in Poland (Chmielarz et al., 2010). 


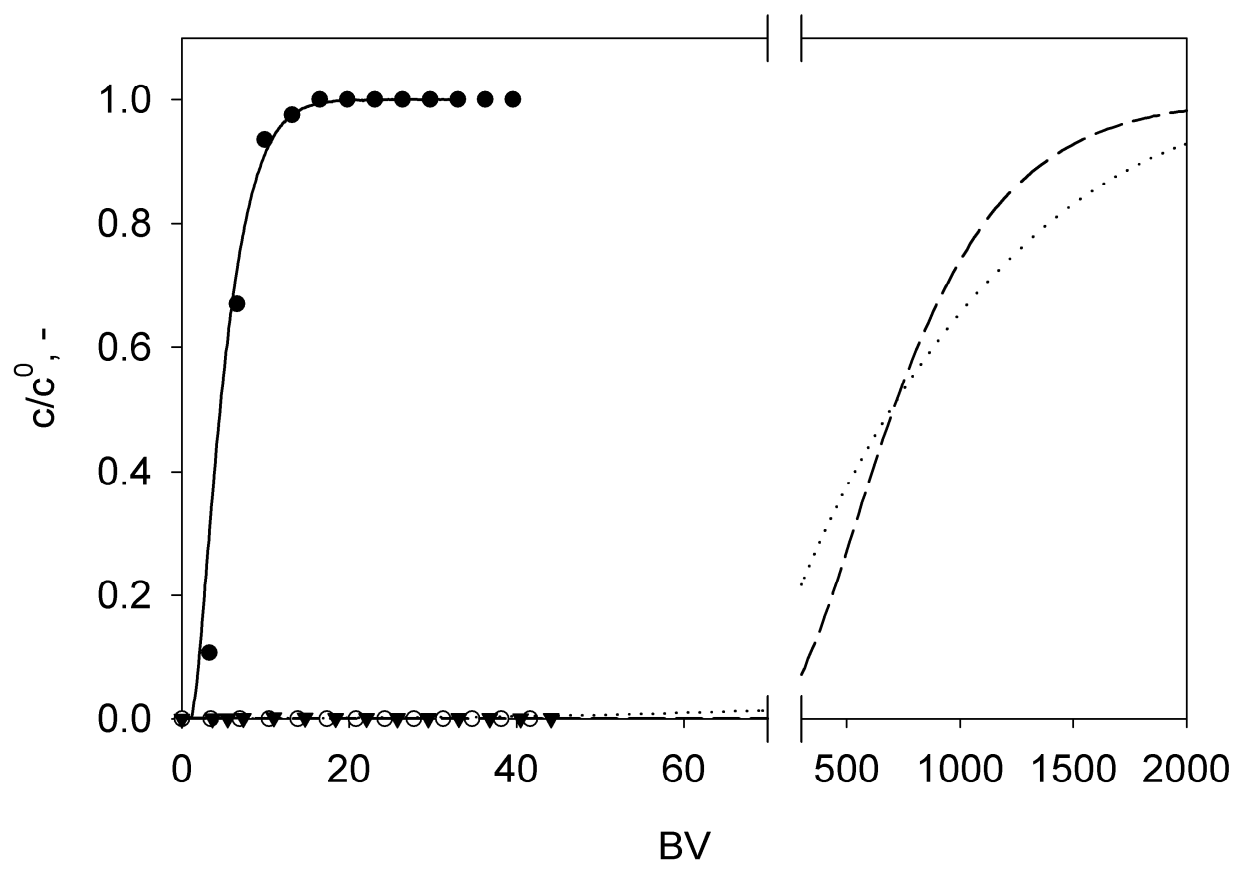

Figure 5. Breakthrough curves of Re with weak anion exchangers from $100 \mathrm{~g} / \mathrm{L} \mathrm{H}_{2} \mathrm{SO}_{4}$ solution with only As as impurity. Analyses of feed solutions are presented in Table 2. $T=25^{\circ} \mathrm{C}$. The symbols stand for the experimental data and the lines simulation results: solid IRA-67, short dash Purolite A170 and long dash Purolite A172.

As it can be seen from Figs. 1 and 5, the Re breakthroughs were not achieved for the Purolite resins within $44 \mathrm{BV}$, and thus full breakthrough curve was measured for A172 with $100 \mathrm{~g} / \mathrm{L} \mathrm{H}_{2} \mathrm{SO}_{4}$ solution containing both Mo and As impurities (Run ID A172 HS/2 in Table 2.). The experiment (results in Fig. 1 and Table 3) was stopped after 786 BV, when dynamic Re capacity of the resin was $73 \mathrm{mg} / \mathrm{mL}_{\text {bed }}$ at $80 \%$ breakthrough. $5 \%$ breakthrough capacity was $33 \mathrm{mg} / \mathrm{mL}_{\text {bed }}$ after $243 \mathrm{BV}$, and based on the simulation at $100 \%$ breakthrough the capacity would be $91.0 \mathrm{mg} / \mathrm{mL}_{\text {bed. }}$. These results are comparable to the literature values as estimated from the breakthrough curves in paper by Blokhin et al. (2011); 5\% and $80 \%$ breakthroughs gave respectively capacities of $\sim 70$ and $\sim 90 \mathrm{mg} / \mathrm{mL}_{\text {bed. }}$. 
The slight difference is explained by higher feed concentration of Re and lower flowrate, which increase the capacities compared to the experiments in this study. In experiment A172 HS/1 (no full breakthrough for Re) the adsorbed amounts of Mo and As based on elution of the loaded resin bed were 0.9 and $1.6 \mathrm{mg} / \mathrm{mL}_{\text {bed, }}$ respectively, giving 95.3 and 53.6 for Re/Mo and Re/As ratios in the loaded bed (Table 3).

Elution of Re with $\mathrm{NH}_{4} \mathrm{OH}$ at $20{ }^{\circ} \mathrm{C}$ from Purolite $\mathrm{A} 172$ resin is known to be difficult when the resin loadings are low (Blokhin et al., 2011; Mal'tseva et al., 2012). In the latter article it is stated that the resin contains $1.1 \%$ of strong base groups as a by-product from the synthesis. However, this alone does not explain the poor elution performance with $\mathrm{NH}_{4} \mathrm{OH}$ since the residual amount of Re after the elution increases with increasing initial saturation, and it also exceeds the amount corresponding to the equivalent amount of the strong base groups. The kinetics of the desorption is also very slow, which is attributed to the very low extent of swelling of the A172 resin in the ammonia solutions. Steric effects can thus be concluded to be partly responsible for the poor equilibrium behavior.

Elution of Re with $\mathrm{NH}_{4} \mathrm{OH}$ from Purolite A170 resin is not as difficult as from A172, yet the complete elution especially in low loadings is not achieved. The amount of the strong base groups is $0.5 \%$, and the macroporous structure makes the inner parts of the resin more accessible (Mal'tseva et al., 2012).

Since the Purolite A172 is superior for Re adsorption from feed solutions containing Mo, overcoming the poor elution performance would be highly desired. Mal'tseva et al. (2012) observed that elution can be significantly enhanced by increasing the temperature and/or by adding ethanol to the eluent to increase swelling, although removal of ethanol 
complicates the flowsheet. It seems, however, that increasing the temperature to $50-60{ }^{\circ} \mathrm{C}$ alone would enhance the elution from fairly highly loaded resin sufficiently to render the whole ion exchange process feasible. Based on the data available (Mal'tseva et al., 2012), reaching over $80 \%$ yield should be possible. The Re containing raffinate obtained by loading the resin to a high extent could be recycled back to feed, or the losses could be avoided by counter-current operation so that highly loaded column would go to elution while the low loaded column would remain in the loading phase. According to the data presented in Table 3, another possibility is to use $\mathrm{NaOH}$, which would desorb $\mathrm{Re}$ effectively.

\section{Conclusions}

In this work, recovering rhenium from molybdenum and arsenic containing $\mathrm{H}_{2} \mathrm{SO}_{4}$ solutions was studied with three weak anion exchangers. Experimental studies were done as batch uptake kinetics and single column experiments, and the system was also modeled. Features of the separation systems were discussed in relation to adsorption theories, thermodynamics and aqueous chemistry of the involved species.

From the studied resins gel-type Purolite A172 with complex amine functionality was clearly the best for the studied solutions, though its slight drawback is an ineffective elution with desired $\mathrm{NH}_{4} \mathrm{OH}$. Purolite A170 with similar functionality, but with macroporous structure, had almost as good Re binding properties, but did not have nearly as good Re/Mo selectivity. Gel-type IRA-67 with tertiary amine functionality had much lower Re capacity and selectivity than the Purolite resins. 
The high Re capacities (good $\mathrm{Re} / \mathrm{SO}_{4}{ }^{2-}$ and $\mathrm{Re} / \mathrm{HSO}_{4}{ }^{-}$selectivities) of the Purolite resins are explained by the affinity of the functional group towards monovalent and more hydrophobic anions. Good Re/Mo and Re/As selectivities of the gel-type A172 resin are explained by the steric effects of the physical structure; the larger Mo and As species can more easily enter the functional groups in the macroporous A170. Because of looser geltype structure of IRA-67 the Mo and As species can also enter the inner parts of the resin, but with denser Purolite A172 Mo species can only access the sites near the particle surface.

The modeling results and batch uptake kinetics data indicated that the selectivities can be explained by differences in the equilibrium behavior. Though, the behavior of Mo in all the column adsorption experiments was not explained by the used models due to the complex aqueous speciation. The conclusion about the steric hindrance of the migration of the oxyanions in the gel-type Purolite A172 resin was verified by the fitted diffusion coefficients, which were several magnitudes smaller than the ones for the other studied resins. Possibility of another Mo binding mechanism, that is chelation of cationic Mo species, was also discussed.

The results of this research show that very specific properties are required from resin for recovering Re from acidic sulfate solutions, especially if containing Mo. 


\section{Acknowledgements}

M.Sc. Javier Vasquez and M.Sc. Mikko Tyster are acknowledged for experimental assistance. Tekes, Fimecc Oy (ELEMET program), OMG Kokkola Chemicals Oy, Outotec Finland Oyj, Norilsk Nickel Harjavalta Oy, Talvivaara Mining Company, and Academy of Finland (Grant No. 252688) are acknowledged for financial support. Purolite ${ }^{\circledR}$ is acknowledged for providing their resins for the experimentation.

\section{References}

Abisheva, Z.S., Zagorodnyaya, A.N., Bekturganov, N.S., 2011. Review of technologies for rhenium recovery from mineral raw materials in Kazakhstan. Hydrometallurgy 109, 1-8. doi:10.1016/j.hydromet.2011.04.014

Amberlite IRA67 Product data sheet [WWW Document], 2008. URL http://www.dow.com/assets/attachments/business/ier/ier_for_industrial_water_tre atment/amberlite_ira67/tds/amberlite_ira67.pdf (accessed 27.10.2014).

Anderson, C.D., Taylor, P.R., Anderson, C.G., 2013. Extractive metallurgy of rhenium: a review. Miner. Metall. Process. 30, 59-73.

Barrett, J., 2003. Inorganic Chemistry in Aqueous Solution, Tutorial Chemistry Texts. The Royal Society of Chemistry.

Blokhin, A.A., Amosov, A.A., Murashkin, Y.V., Evdoshenko, S.A., Mikhailenko, M.A., Nikitin, N.V., 2005. Sorption of Rhenium(VII) on Gel and Macroporous Anion Exchangers of Different Basicities from Solutions of Mineral Acids and Their Ammonium Salts. Russ. J. Appl. Chem. 78, 1411-1415. doi:10.1007/s11167-0050528-0

Blokhin, A.A., Maltseva, E.E., Pleshkov, M.A., Murashkin, Y.V., Mikhaylenko, M.A., 2011. Sorption recovery of rhenium from acidic sulfate and mixed nitrate-sulfate solutions containing molybdenum. Presented at the 7th International Symposium on Technetium and Rhenium - Science and Utilization, Moscow.

Casas, J.M., Alvarez, F., Cifuentes, L., 2000. Aqueous speciation of sulfuric acid-cupric sulfate solutions. Chem. Eng. Sci. 55, 6223-6234. doi:10.1016/S00092509(00)00421-8 
Chmielarz, A., Benke, G., Leszczynska-Sejda, K., Anyszkiewicz, K., Litwinionek, K., 2010. Development of the technology for recovery of rhenium in polish copper smelters. GDMB Informations GmbH, pp. 1803-1814.

Chung, S.F., Wen, C.Y., 1968. Longitudinal dispersion of liquid flowing through fixed and fluidized beds. AIChE J. 14, 857-866. doi:10.1002/aic.690140608

Churchward, P.E., Rosenbaum, J.B., 1963. Sources and recovery methods for rhenium. Bur. Mines Rep. Invest. No. 6246, 16 pp.

Coltrinari, E.L., Hazen, W.W., Ketcham, V.J., 2000. Pressure oxidation process for the production of molybdenum trioxide from molybdenite concentrate. US6149883A.

Cotton, F.A., Wilkinson, G., 1988. Advanced inorganic chemistry. Wiley \& Sons, New York.

Dudev, T., Lim, C., 2004. Oxyanion Selectivity in Sulfate and Molybdate Transport Proteins: An ab Initio/CDM Study. J. Am. Chem. Soc. 126, 10296-10305. doi:10.1021/ja047951n

Elutin, A.V., Istrashkina, M.V., Peredereeva, Z.A., 1997. Rhenium recovery from secondary raw materials of various types. Minerals, Metals \& Materials Society, pp. $135-139$.

Goddard, J.B., 1983. Recovery of rhenium from uranium in-situ leach liquor. Trans. Am. Inst. Min., Metall., Pet. Eng., Soc. Min. Eng. AIME 274, 1996-2000.

Graedel, T.E., Allwood, J., Birat, J.-P., Buchert, M., Hagelueken, C., Reck, B.K., Sibley, S.F., Sonnemann, G., 2011. Recycling Rates of Metals: A Status Report - A Report of the Working Group on Global Metal Flows to the International Resource Panel. UNEP.

Helfferich, F., 1995. Ion Exchange. Dover Publications, Inc.

Heshmatpour, B., McDonald, R.E., 1982. Recovery and refining of rhenium, tungsten and molybdenum from tungsten-rhenium, molybdenum-rhenium, and other alloy scraps. J. Less-Common Met. 86, 121-8. doi:10.1016/0022-5088(82)90196-5

Holm, R.H., Kennepohl, P., Solomon, E.I., 1996. Structural and Functional Aspects of Metal Sites in Biology. Chem. Rev. 96, 2239-2314. doi:10.1021/cr9500390

Laatikainen, M., Sirola, K., Paatero, E., 2007. Binding of transition metals by soluble and silica-bound branched poly(ethyleneimine). Part I: Competitive binding equilibria. Colloid. Surface. A 296, 191-205. doi:10.1016/j.colsurfa.2006.09.044

Kasikov, L.G., Petrova, A.M., 2009. Processing of deactivated platinum-rhenium catalysts. Theor. Found. Chem. Eng. 43, 544-552. doi:10.1134/S0040579509040320 
Kholmogorov, A.G., Kononova, O.N., Kachin, S.V., Ilyichev, S.N., Kryuchkov, V.V., Kalyakina, O.P., Pashkov, G.L., 1999. Ion exchange recovery and concentration of rhenium from salt solutions. Hydrometallurgy 51, 19-35. doi:10.1016/S0304386X(98)00064-4

KTH - Chemistry / Chemical Equilibrium Diagrams, n.d.

Lebedev, K.B., Tyurekhodzaeva, T.S., 1966. Separation of rhenium from acidic solutions by ion-exchange. Tr. Inst. Metall. Obogashch., Akad. Nauk Kaz. SSR 17, 112-18.

Material Processing Technology - News Listing [WWW Document], 2014. URL http://www.mpt-llc.com/News/MPT-News-Nov-08.htm (accessed 27.10.2014).

Mal'tseva, E.E., Blokhin, A.A., Murashkin, Y.V., 2012. Specific features of rhenium desorption from weakly basic anion exchangers Purolite A170 and Purolite A172 with ammonia solutions. Russ. J. Appl. Chem. 85, 1034-1040. doi:10.1134/S1070427212070075

Marcus, Y., 2015. Ions in solution and their solvation. John Wiley \& Sons, Inc, Hoboken, New Jersey.

Mekler, L.I., 1975. Sorption extraction of rhenium at the Balkhash mining and metallurgy plant. Tsvetn. Met. 42-47.

Melaven, A.D., Bacon, J.A., 1947. Process for Recovering Rhenium. US2414965A.

Metal pages [WWW Document], 2014. URL http://www.metal-pages.com/ (accessed 27.10.2014).

Mikhaylenko, M.A., 2011. Purolite ${ }^{\circledR}$ ion exchange resins for recovery and purification of rhenium. Presented at the 7th International Symposium on Technetium and Rhenium - Science and Utilization, Moscow.

Mikhaylenko, M.A., Blokhin, A.A., 2012. Ion exchange resins tailored for effective recovery and separation of rhenium, molybdenum and tungsten. Presented at the SME Annual Meeting, Seattle, WA.

Nebeker, N., 2012. Method for rhenium recovery from copper solvent extraction solution. US20120152063A1.

Nebeker, N., Hiskey, J.B., 2012. Recovery of rhenium from copper leach solution by ion exchange. Hydrometallurgy 125-126, v64-68. doi:10.1016/j.hydromet.2012.05.008

Olazabal, M.A., Orive, M.M., Fernández, L.A., Madariaga, J.M., 1992. Selective Extraction of Vanadium (V) from Solutions Containing Molybdenum (VI) by 
Ammonium Salts Dissolved in Toluene. Solvent Extr. Ion Exch. 10, 623-635. doi:10.1080/07366299208918125

Olbrich, A., Meese-Marktscheffel, J., Jahn, M., Zertani, R., Stoller, V., Erb, M., Heine, K.H., Kutzler, U., 2009. Recycling of superalloys with the aid of an alkali metal salt bath. US20090255372.

$\begin{array}{llll}\text { Purolite Products } \quad \text { [WWW } & \text { Document], } & \text { URL }\end{array}$ http://www.purolite.com/RelId/606257/ISvars/default/Products.htm (accessed 27.10.2014).

Schiesser, W.E., 1991. The Numerical Method of Lines: Integration of Partial Differential Equations. Academic Press.

Sole, K.C., Cole, P.M., Feather, A.M., Kotze, M.H., 2011. Solvent extraction and ion exchange applications in Africa's resurging uranium industry: A review. Solvent Extr. Ion Exch. 29, 868-899. doi:10.1080/07366299.2011.581101

Srivastava, R.R., Kim, M., Lee, J., Jha, M.K., Kim, B.-S., 2014. Resource recycling of superalloys and hydrometallurgical challenges. J. Mater. Sci. 49, 4671-4686. doi:10.1007/s10853-014-8219-y

Srivastava, R.R., Lee, J., Kim, M., 2015. Complexation chemistry in liquid-liquid extraction of rhenium. J. Chem. Technol. Biotechnol. In press. doi: $10.1002 /$ jctb.4707

Stoller, V., Olbrich, A., Meese-Marktscheffel, J., Mathy, W., Erb, M., Nietfeld, G., Gille, G., 2008. Process for electrochemical decomposition of superalloys. US20080110767A1.

Sutulov, A., 1965. Molybdenum Extractive Metallurgy. University of Concepcion.

Tanaka, M., Takahashi, Y., Yamaguchi, N., Kim, K.-W., Zheng, G., Sakamitsu, M., 2013. The difference of diffusion coefficients in water for arsenic compounds at various $\mathrm{pH}$ and its dominant factors implied by molecular simulations. Geochim. Cosmochim. Ac. 105, 360-371. doi:10.1016/j.gca.2012.12.004

Troshkina, I.D., Shilyaev, A.V., Abdrakhimanov, T.G., Maiboroda, A.B., 2011. Rhenium in unconventional raw materials: distribution and feasibility of recovery. Razved. Okhr. Nedr 87-90.

United States Geological Survey, 2014. Mineral Commodity Summaries 2014, Mineral Commodity Summaries. U.S. Geological Survey.

Virolainen, S., Heinonen, J., Paatero, E., 2013. Selective recovery of germanium with Nmethylglucamine functional resin from sulfate solutions. Sep. Purif. Technol. 104, 193-199. doi:10.1016/j.seppur.2012.11.023 
Virolainen, S., Suppula, I., Sainio, T., 2014. Continuous ion exchange for hydrometallurgy: Purification of $\mathrm{Ag}(\mathrm{I})-\mathrm{NaCl}$ from divalent metals with aminomethylphosphonic resin using counter-current and cross-current operation. Hydrometallurgy 142, 8493. doi:10.1016/j.hydromet.2013.11.012

Virolainen, S., Tyster, M., Haapalainen, M., Sainio, T., 2015. Ion exchange recovery of silver from concentrated base metal-chloride solutions. Hydrometallurgy 152, 100 106. doi:10.1016/j.hydromet.2014.12.011

Waterman, B.T., Dixon, S.N., Morelli, T.L., Owusu, G., Ormsby, S.T., 2010. Methods and systems for recovering rhenium from a copper leaching solution. WO2010120405A1.

Wroński, M., 1997. Fingerprint of anions involving pKa, mobility and concentration established by using capillary isotachophoresis. J. Chromatogr. A 772, 19-25. doi:10.1016/S0021-9673(97)00141-6

Yao, C., Tien, C., 1993. Approximations of uptake rate of spherical adsorbent pellets and their application to batch adsorption calculations. Chem. Eng. Sci. 48, 187-198. doi:10.1016/0009-2509(93)80295-2

Zagorodnyaya, A.N., Lebedev, K.B., Briksman, B.S., 1970. Effect of associated anions (sulfates, chlorides, and nitrates) on the ion-exchange sorption of rhenium from molybdenum-containing solutions. Tr., Gos. Nauch.-Issled. Proekt. Inst. Obogashch. Rud Tsvet. Metal. Kazmekhanobr No. 3, 125-135.

Zagorodnyaya, A.N., Abisheva, Z.S., Ponomareva, E.I., Bekturganov, N.S., 2008. Hydrometallurgical processing of rhenium-containing by-products of lead production. Science Press, pp. 2975-2985.

Zagorodnyaya, A.N., Abisheva, Z.S., Sharipova, A.S., Sadykanova, S.E., Bochevskaya, Y.G., Atanova, O.V., 2013. Sorption of rhenium and uranium by strong base anion exchange resin from solutions with different anion compositions. Hydrometallurgy 131-132, 127-132. doi:10.1016/j.hydromet.2012.11.003

Zhao, Z., Yang, Y., Xiao, Y., Fan, Y., 2012. Recovery of gallium from Bayer liquor: A review. Hydrometallurgy 125-126, 115-124. doi:10.1016/j.hydromet.2012.06.002 